\title{
Speciation of Trace Levels of Chromium with Bismuth Modified Pyrolyzed Photoresist Carbon Electrodes
}

\author{
Andrea Mardegan ${ }^{[a]}$ Mattia Cettolin,${ }^{[b]}$ Rahul Kamath, ${ }^{[c]}$ Veronica Vascotto,${ }^{[a]}$ Angela Maria Stortini, ${ }^{[b]}$ \\ Paolo Ugo, ${ }^{[b]}$ Paolo Scopece, ${ }^{[a]}$ Marc Madou, ${ }^{[c, d, e]}$ and Ligia Maria Moretto ${ }^{* b]}$
}

\begin{abstract}
Pyrolyzed photoresist carbon electrodes modified with bismuth (Bi-PPCEs) were prepared and used for the determination of trace levels of chromium. In order to lower the detection limit, the choice of the supporting electrolyte concentration and electroanalytical parameters were optimized. The adsorptive cathodic stripping voltammetric determination of $\mathrm{Cr}(\mathrm{VI})$ at Bi-PPCE
\end{abstract}

was selective even in the presence in $\mathrm{Cr}$ (III). A detection limit of $0.1 \mathrm{mgL} \square 1$ was obtained after $60 \mathrm{~s}$ preconcentration. After oxidation with UV light and oxygen, all chromium species were oxidized to $\mathrm{Cr}(\mathrm{VI})$ and the total inorganic $\mathrm{Cr}$ determination is possible. Finally, Bi-PPCE was applied to trace $\mathrm{Cr}(\mathrm{VI})$ analysis in real samples such as waste water and tap water.

Keywords: Pyrolyzed photoresist carbon electrode · Bismuth film electrode · Chromium · Adsorptive cathodic stripping voltammetry $\cdot$ Speciation analysis.

\section{Introduction}

At the end of the last century, the phenomenon called "mercurophobia" caused many researchers to start studying possible alternatives for mercury electrodes. Bismuth modified electrodes were proposed for the first time by Wang et al. in 2000 [1] as an alternative to mercury electrodes. Compared to other "environmental friendly" electrode materials, such as silver [2], iridium [3], several alloys [4] and different configurations of carbon [5], bismuth displayed better electroanalytical performance and therefore has been commonly accepted as a suitable replacement for mercury.

Bismuth electrodes have been successfully applied in anodic [6-8] and adsorptive cathodic stripping voltammetry (AdCSV) [9-14]. The latter technique relies on the interfacial accumulation of a complex of the target metal on the surface of the working electrode and constitutes an interesting alternative approach to classical anodic stripping voltammetry particularly useful for analytes that do not form an amalgam/alloy [15-17].

Among hazardous metal ions, chromium(VI) is widely used in several industrial processes (metal plating, leather tanning, paint making, etc.), and is one of the most harmful inorganic pollutants because of its high toxicity. Therefore, the analysis of $\mathrm{Cr}(\mathrm{VI})$ constitutes an issue of general concern in particular for the difficulties relating to its speciation. Analyses of $\mathrm{Cr}(\mathrm{VI})$ by AdCSV with mercury electrodes have been performed using different complexing agents such as diethylene triamine pentaacetic acid (DTPA) [18,19], cupferon [20] or pyrocatechol violet (PCV) [21,22]. Recently, bismuth modified electrodes have been proposed as a valid alternative to $\mathrm{Hg}$ also for the AdCSV of $\mathrm{Cr}(\mathrm{III})$ and $\mathrm{Cr}(\mathrm{VI})$, using the above cited ligands [23-25].
In this paper we report the application of a new kind of carbon electrodes, namely pyrolyzed photoresist carbon electrodes (PPCE) for the speciation of chromium(VI). These carbon electrodes were first proposed by Madou et al [26-28] and are conveniently fabricated employing simple and inexpensive batch fabrication methodologies, i.e., UV photolithography followed by pyrolysis. The latter is carried out in a flow of $\mathrm{N}_{2}$ gas with standard temperature ramp-up of about $108 \mathrm{C} / \mathrm{min}$ and a one hour dwell time at the maximum temperature of $9008 \mathrm{C}$, followed by the natural cooling of the furnace. For more details on this C-MEMS process consult a recently optimized microfabrication procedure [29]. PPCEs display an electrochemical behaviour comparable to that of "classical" glassy carbon electrodes, with the advantage of

[a] A. Mardegan, V. Vascotto, P. Scopece

Veneto Nanotech

Via delle Industrie 5, 30175, Venice-Marghera, Italy

[b] M. Cettolin, A. M. Stortini, P. Ugo, L. M. Moretto Department of Molecular Sciences and Nanosystems, University $\mathrm{Ca} \square$ Foscari of Venice

S. Marta 2137, Venice, Italy

*e-mail:moretto@unive.it

[c] R. Kamath, M. Madou

Department of Biomedical Engineering, University of California

Irvine, CA, USA 92697

[d] M. Madou

Department of Mechanical and Aerospace Engineering, University of California

Irvine, CA, USA 92697

[e] M. Madou

Materials and Manufacturing Technology, University of California

Irvine, California 92697, USA 
being cheaper and with the possibility of a customized design.

In this research, we study the preparation, characterization and analytical application of bismuth modified PPCEs (Bi-PPCEs) with the aim of applying them to the determination and redox speciation of chromium ions in water samples. The use of Bi-PPCE for inorganic chromium analysis and speciation allows for the quick and lowcost determination of this toxic analyte using cheap but highly reliable electrodes.

\section{Experimental}

\subsection{Reagents and Materials}

Standard solutions of Bi(III) (1000 mg L ${ }^{\square 1}$ ) (Merck) were prepared and diluted as required with $0.01 \mathrm{molL}^{\square 1} \mathrm{HCl}$. Standard $\mathrm{Cr}(\mathrm{VI})$ solution (1000 $\mathrm{mgL}^{\square 1}$ ) was prepared by dissolving the appropriate amount of potassium dichromate (Carlo Erba) in water. All other reagents were analytical grade (Sigma Aldrich, and Fluka) and used without any further purification.

SU-8 and its developer were purchased from MicroChem Inc, MA (USA).

\subsection{Apparatus}

Voltammetric measurements were carried out at room temperature (22 8C) and performed using a CHI440 electrochemical workstation. A three-electrode single-compartment electrochemical cell $(20 \mathrm{~mL})$ was used for all experiments with the PPCE as the working electrode, a platinum coil as the counter electrode and a KCl-saturated $\mathrm{Ag} / \mathrm{AgCl}$ as the reference electrode.

\subsection{Procedures}

\subsubsection{PPCE Preparation}

A negative tone epoxy based photoresist, SU-8, was photo-patterned employing standard UV photolithography. The wafers were dehydrated for 30 minutes at $1208 \mathrm{C}$ right before the application of the photoresist. Briefly, the photoresist was applied manually on the wafers and then spun to reach the desired thickness, following the manufacturer s specifications [30]. After deposition, the casting solvent was evaporated from the photoresist in the soft or pre-bake step that is performed at 958 on a hot plate to facilitate the evaporation of the solvent from the bulk of the polymer. The resist was then exposed to UV light $(365 \mathrm{~nm})$ which activates the catalyst for the cross-linking reaction. After a post-exposure bake, to fully polymerize the SU-8, the patterned features were developed. In this step, the un-polymerized SU-8 is dissolved upon immersion in a developer. The patterned structures (shown in Figure 1A) were carbonized using a three-step pyrolysis process in an open ended alumina-tube furnace. In the first step the samples were heated at 3008 for 1 hour, under $\mathrm{N}_{2}$ (flow rate: $2000 \mathrm{sccm}$ ). The temperature was

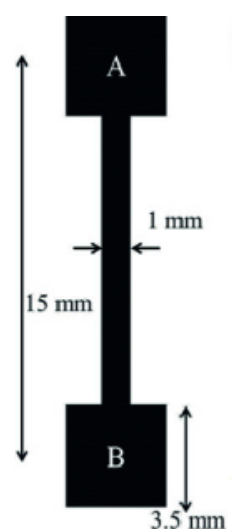

(A)

(B)

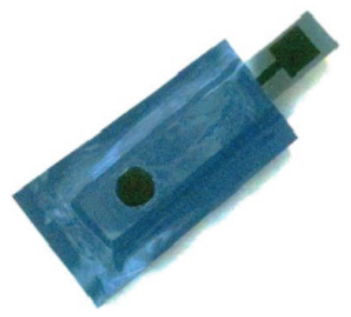

Fig. 1. (A) Scheme of the electrode design; (B) photograph of the electrode in (A) after pyrolysis and insulation with Monokote tape.

then ramped at a rate of $108 \mathrm{C} / \mathrm{min}$ up to $9008 \mathrm{C}$. The samples were kept at the final pyrolysis temperature for 1 hour before cooling. The electrodes were insulated with Monokote (Topflite, Champaign IL) tape so that only a well-defined geometric area was exposed $\left(0.07 \mathrm{~cm}^{2}\right)$ to the solution during the electrochemical measurements (see Figure 1B).

\subsubsection{AFM Measurements}

AFM measurements were performed in air on samples dried at room conditions, using a Veeco NS IV Dimension 3100 Scanning Probe Microscope. Images were collected in Tapping mode using standard silicon cantilevers with typical resonant frequency of $150 \mathrm{kHz}$ and elastic constant of $5 \mathrm{~N} / \mathrm{m}$. The surface roughness was calculated as the root mean square average of the roughness profile ordinates.

\subsubsection{Analytical Procedures}

For the electroanalysis of $\mathrm{Cr}(\mathrm{VI})$ ex-situ modification of the PPCE substrate was performed. During the plating step, the PPCE was placed in $0.1 \mathrm{M}$ acetate buffer ( $\mathrm{pH} 4.5$ ), $1 \mathrm{mgL}^{\square 1} \mathrm{Bi}(\mathrm{III})$ solution. After an electrochemical cleaning step $(+0.5 \mathrm{~V}$ for $120 \mathrm{~s})$, bismuth was potentiostatically deposited at $\square 1.2 \mathrm{~V}$ for $300 \mathrm{~s}$ under stirring conditions. Afterwards, the Bi-PPCE was placed in an electrochemical cell together with $0.5 \mathrm{mmol} \mathrm{L}^{\square} \mathrm{PCV}$ and $0.1 \mathrm{molL}^{\square 1} \mathrm{NaNO}_{3}$ in $0.01 \mathrm{molL}^{\square 1}$ acetate buffer (pH 6). After accumulation (adsorption) at $\square 0.2 \mathrm{~V}$ for $60 \mathrm{~s}$, followed by a $15 \mathrm{~s}$ equilibration step, a cathodic stripping square-wave (SW) voltammogram from $\square 0.2 \mathrm{~V}$ to $\square 1.2 \mathrm{~V}$ was recorded, with a frequency of $25 \mathrm{~Hz}$, a potential step of $5 \mathrm{mV}$ and an amplitude of $50 \mathrm{mV}$. After each measurement, a cleaning step was performed by keeping the potential at $\square 1.4 \mathrm{~V}$ for $20 \mathrm{~s}$.

The total inorganic $\mathrm{Cr}$ concentration was determined by first oxidizing $\mathrm{Cr}(\mathrm{III})$ to $\mathrm{Cr}(\mathrm{VI})$. This can be carried out avoiding chemical contamination by using UV irradiation of an oxygen-saturated solution. A photochemical 

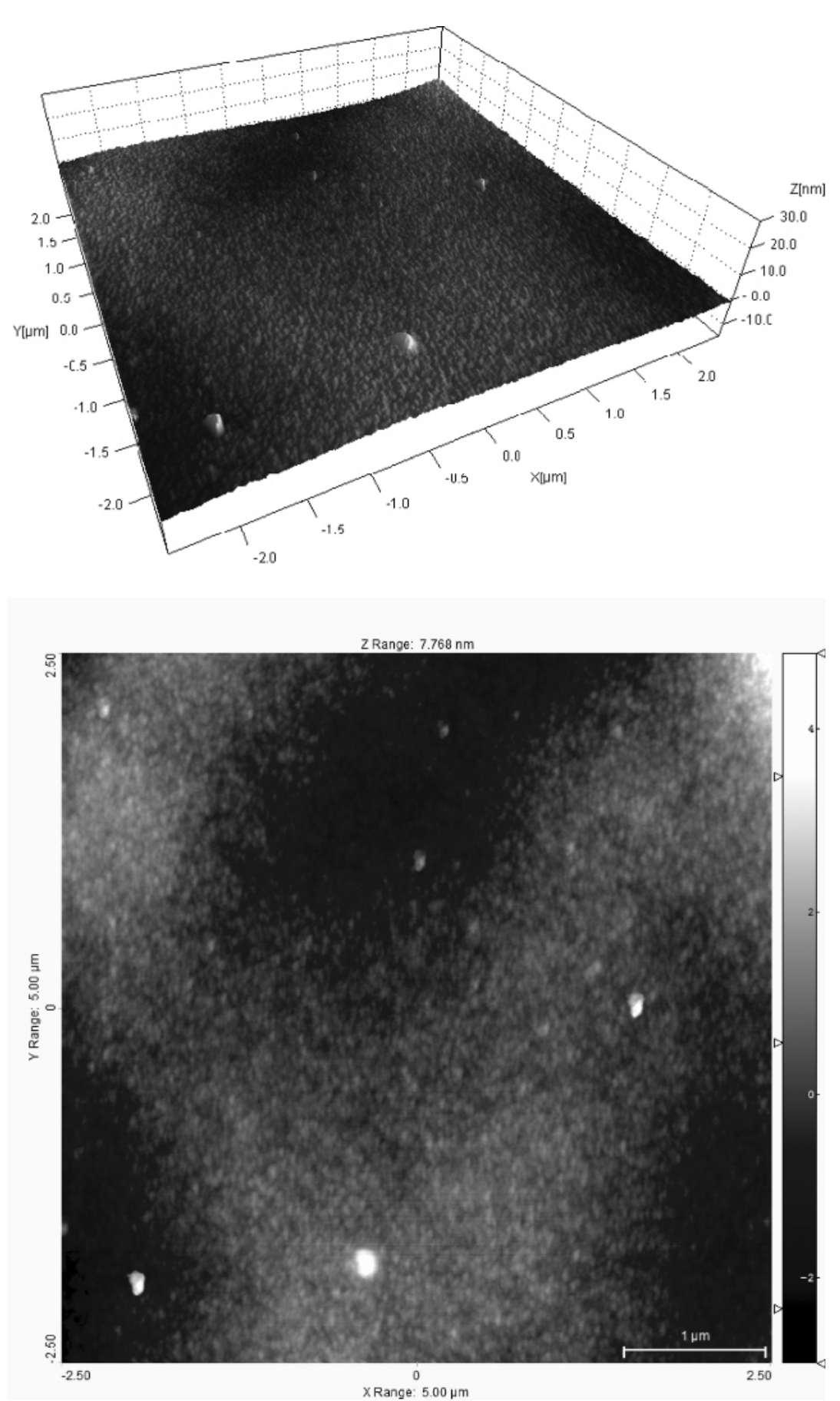

Fig. 2. AFM topographic images of the surface of a Pyrolyzed Photoresist Carbon Electrode. On the top the topography of the surface, below the corresponding 3D topography.

reactor was designed for $\mathrm{Cr}(\mathrm{III})$ oxidation, consisting of a 20 -mL quartz cell; the cell was irradiated by a $400 \mathrm{~W}$ medium pressure mercury vapor lamp (Hanovia).

Prior to and during the irradiation, (usually $30 \mathrm{mi}-$ nutes), the solution was continually purged with high purity $\mathrm{O}_{2}$ (SAPIO). Ozone formed in this process is able to effectively oxidize $\mathrm{Cr}(\mathrm{III})$ to $\mathrm{Cr}(\mathrm{VI})$, according to $\mathrm{Re}$ action 1:

\section{$\mathrm{O}_{3}$ p 2 CrðIIPp $6 \mathrm{H}^{\mathrm{p}}$ ! 2 CrðVIpp $3 \mathrm{H}_{2} \mathrm{O}$}

\section{Results and Discussion}

\subsection{AFM Characterization of the PPCE}

Previous studies performed by Madov et al. [26,28] established the glassy carbon nature of PPCE films. Here we are reporting in some more detail the microscopic morphological features of PPCE. To this aim, at first, the morphological characteristics of the PPCE surface were studied by AFM. Figure 2 shows the topography of the surface of the electrode with relevant 3-D profile. AFM 


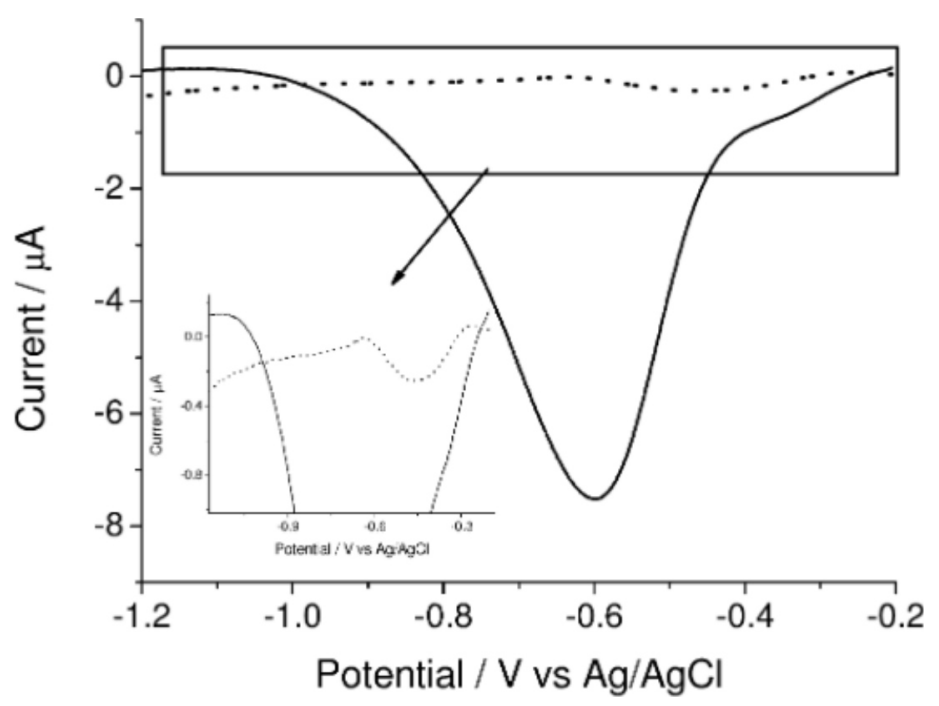

Fig. 3. AdCSVs at the ex-situ prepared Bi-PPCE in solution of $10 \mathrm{mgL} \mathrm{L}^{\square}$ of $\mathrm{Cr}(\mathrm{VI})$, acetate buffer $0.01 \mathrm{molL}^{\square 1}$ (pH 6) and $0.5 \mathrm{mmolL}{ }^{\square} \mathrm{PCV}$ in the presence (solid line) and in the absence (dotted line) of $0.1 \mathrm{molL}^{\square 1} \mathrm{NaNO}_{3}$. Accumulation at $\square 0.2 \mathrm{~V}$ for $60 \mathrm{~s}$; equilibration time of $15 \mathrm{~s}$; SWV parameters: frequency of $25 \mathrm{~Hz}$, potential step of $5 \mathrm{mV}$ and amplitude of $50 \mathrm{mV}$.

measurements were carried out over an area of $5 \square 5 \mathrm{~mm}$ with a resolution of 5.243 point per $\mathrm{mm}^{2}$. From these data a surface roughness of $0.8 \mathrm{~nm}$ was obtained. This value is about four times lower than the one obtained for a mirror polished glassy carbon electrode [31]. This demonstrates that the photolithographic deposition of a photoresist followed by pyrolysis performed in the previously optimized experimental conditions [26,29] produces very flat carbon surfaces with negligible roughness.

\subsection{Optimization of the Experimental Conditions for Cr (VI) Analysis}

In this work, we used PCV as the complexing agent for the determination of $\mathrm{Cr}(\mathrm{VI})$ via AdCSV [21-23]. This ligand was chosen on the basis of preliminary tests in which PCV was demonstrated to be more suitable to the present aim in comparison with DTPA. The mechanism of the complexation reaction with $\mathrm{PCV}$ involves the oxidation of the ligand by $\mathrm{Cr}(\mathrm{VI})$, producing $\mathrm{Cr}(\mathrm{III})$ and $\mathrm{PCV}_{\mathrm{ox}}$ (Reaction 2); this is followed by complexation of $\mathrm{Cr}$ (III) by $\mathrm{PCV}_{\text {ox }}$ (Reaction 3) which is finally adsorbed on the electrode surface by the application of a potential between $\square 0.2$ and $0 \mathrm{~V}$.

CrðVIPp PCV! CrỡIIPp PCV ox

PCV $_{\text {ox }}$ p Crð̆IIIP! $\quad$ PCV $_{\text {ox }} \square$ CrŏIIIIPads $_{\text {a }}$

ð3

It is worth mentioning that unoxidized PCV can also bind $\mathrm{Cr}(\mathrm{III})$, but the resulting complex is not electroactive [32]. This behavior ensures one that the observed electrochemical signal is exclusively due to $\mathrm{Cr}(\mathrm{VI})$.

The adsorptive cathodic stripping signal is enhanced by the presence of nitrate ions that reoxidize $\mathrm{Cr}$ (II) ions pro- duced in the electrochemical reduction of the complex (Reactions 4 and 5) [32]:

PCV $_{\text {ox }} \square$ CrŏIIIP $_{\text {ads }} p \mathrm{e}^{\square} !$ PCV $_{\text {ox }} \square$ CrðIP

$\mathrm{PCV}_{\mathrm{ox}} \square$ CrđIIPp $\mathrm{NO}_{3}{ }^{\square} 2 \mathrm{H}^{\mathrm{p}}$ !

$$
\mathrm{PCV}_{\text {ox }} \square \text { CrŏIIIIP ads }_{\text {p }} \mathrm{NO}_{2} \mathrm{p} \mathrm{H}_{2} \mathrm{O}
$$

Figure 3 displays the AdCSVs of $10 \mathrm{mg} \mathrm{L}^{\square 1}$ of $\mathrm{Cr}$ (VI) in the presence (solid line) and in absence (dotted line) of $0.1 \mathrm{molL}^{\square} \mathrm{NaNO}_{3}$. The inset shows the signal recorded in the absence of $\mathrm{NO}_{3}$ and evidences the great enhancement of the peak of the adsorbed complex due to $\mathrm{NO}_{3}$ ions, leading to improved sensitivity and lower detection limits.

In the presence of $\mathrm{NO}_{3}$ a shift in the reduction peak is observed. A possible explanation to this behavior can be the fact that in the presence of $\mathrm{NO}_{3}$ ions the signal sums the contributions given by the adsorbed species and the species coming from the catalytic cycle described by the Reactions 4 and 5.

Figure 4 (full line) shows the Bi stripping voltammogram recorded at a PPCE in acetate buffer $(\mathrm{pH} 6)$ after deposition at $\square 1.2 \mathrm{~V}$ for $60 \mathrm{~s}$ from a solution containing $1 \mathrm{mgL}^{\square 1}$ of $\mathrm{Bi}(\mathrm{III})$. In the same Figure, the dotted line describes the cyclic voltammogram of PCV at a Bi-PPCE in the same medium; the initial cathodic scan has a peak at $\square 0.5 \mathrm{~V}$ corresponding to $\mathrm{PCV}$ reduction, a species that is reoxidized in the anodic scan, displaying a quasi-ideal reversible reaction. These results suggest that the complex $\mathrm{Cr}(\mathrm{III})-\mathrm{PCV}$ can be adsorbed on the electrode at potential values between $\square 0.3$ and $\square 0.1 \mathrm{~V}$, where PCV is not electrochemically reduced and $\mathrm{Bi}(0)$ is not oxidized. In particular, for the following experiments a potential of $\square 0.2 \mathrm{~V}$ was chosen. 


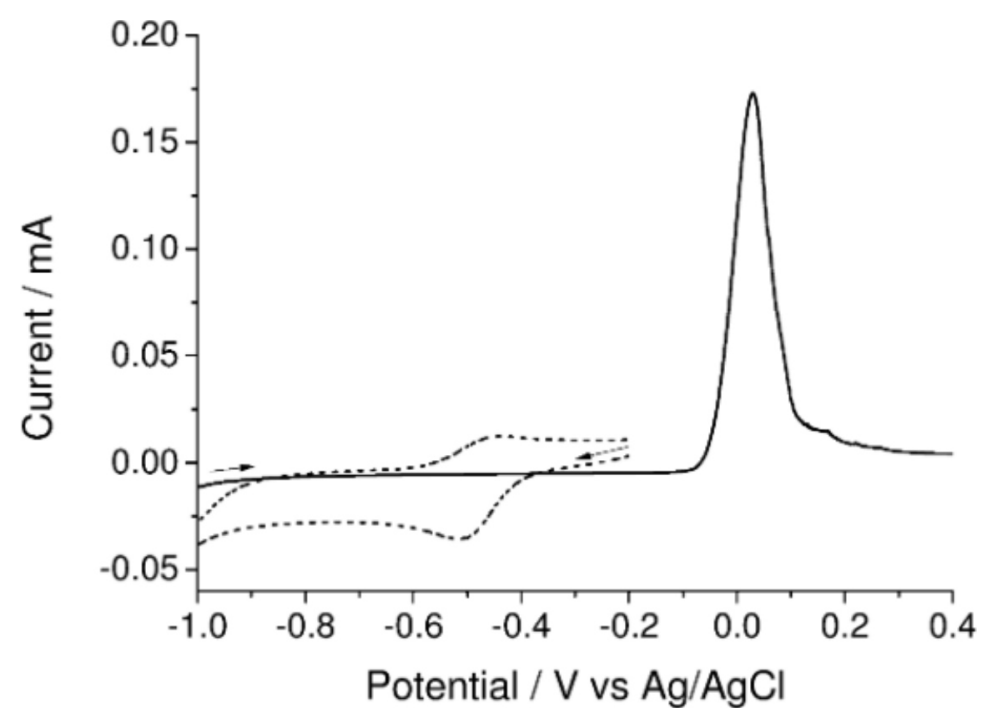

Fig. 4. Full line, LSV at the Bi-PPCE of $1 \mathrm{mgL}^{\square 1} \mathrm{Bi}(\mathrm{III})$ at scan rate of $50 \mathrm{mV} \mathrm{s}{ }^{\square}$. Dotted Line, CV at the Bi-PPCE of $1 \mathrm{mM}$ PCV at scan rate of $50 \mathrm{mV} \mathrm{s}^{\square}$.

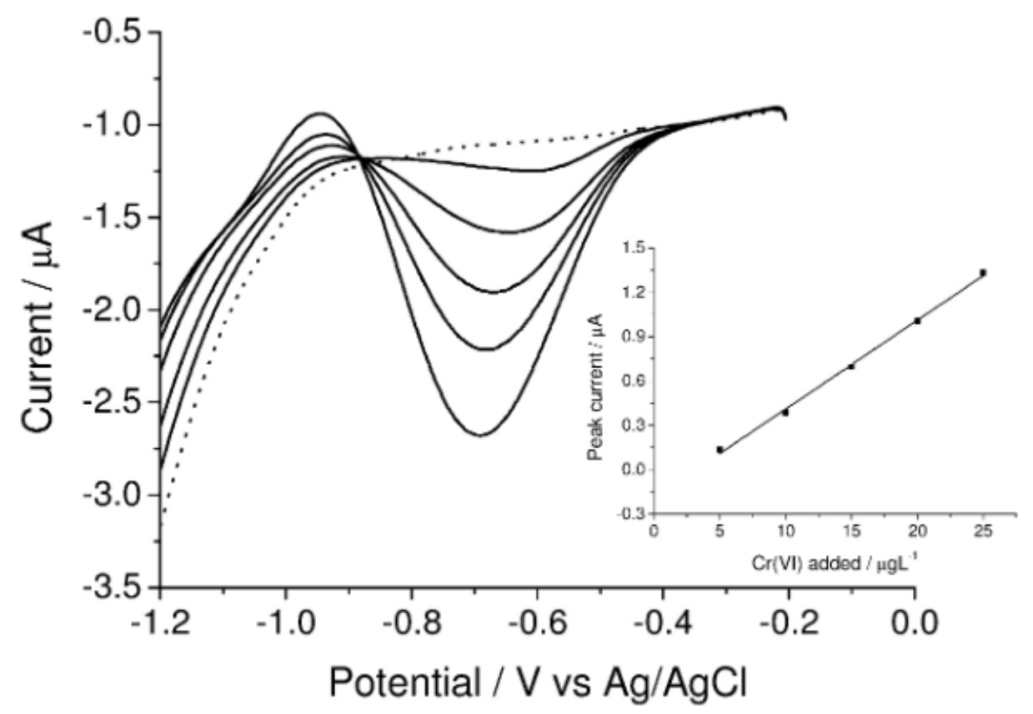

Fig. 5. AdCSVs at the ex-situ prepared Bi-PPCE in solution $5 \mathrm{mgL}^{\square 1}$ of $\mathrm{Cr}(\mathrm{III})$ for increasing concentrations of $\mathrm{Cr}(\mathrm{VI})$ in the range of 5-25 mg L ing calibration plot. Other parameters are as in Figure 3.

\subsection{Determination of $\mathrm{Cr}(\mathrm{VI})$ in the Presence of $\mathrm{Cr}(\mathrm{III})$}

In order to verify the possibility to perform the redox speciation of inorganic chromium, the selectivity of our method to $\mathrm{Cr}(\mathrm{VI})$ was verified. The dotted line voltammogram in Figure 5 presents the CSV recorded at a BiPPCE in a solution containing $\mathrm{Cr}$ (III): the pattern is identical to the blank signal. On the other hand, when increasing the concentration of $\mathrm{Cr}(\mathrm{VI})$ from 5 to $25 \mathrm{mgL}$ a well defined peak is detected at $\square 0.65 \mathrm{~V}$, whose peak current increases linearly with the concentration of $\mathrm{Cr}(\mathrm{VI})$ (see inset in Figure 5). This behaviour illustrates the selectivity of the proposed method to $\mathrm{Cr}(\mathrm{VI})$ detection over $\mathrm{Cr}(\mathrm{III})$. The data represent a good linear calibration plot obtained using an accumulation time of $60 \mathrm{~s}$.
A detection limit (DL) of $0.1 \mathrm{mgL}^{\square 1}$ was calculated by using the $3 \mathrm{~s}_{\mathrm{b}} / \mathrm{m}$ criterion, where $\mathrm{s}_{\mathrm{b}}$ is the standard deviation of the blank and $\mathrm{m}$ is the slope of the calibration plot. The calculated DL is comparable or lower than those obtained with other electroanalytical methods[2325].

\subsection{Determination of Total Inorganic $\mathrm{Cr}$ in Waste Water}

The applicability of the proposed method to the analysis of total inorganic $\mathrm{Cr}$ in a complex matrix was tested analyzing samples of industrial waste-water. After sampling, the water was filtered $(0.45 \mathrm{~mm})$ and acidified with nitric acid ( $\mathrm{pH}$ 2.0) following the standard procedure used for 


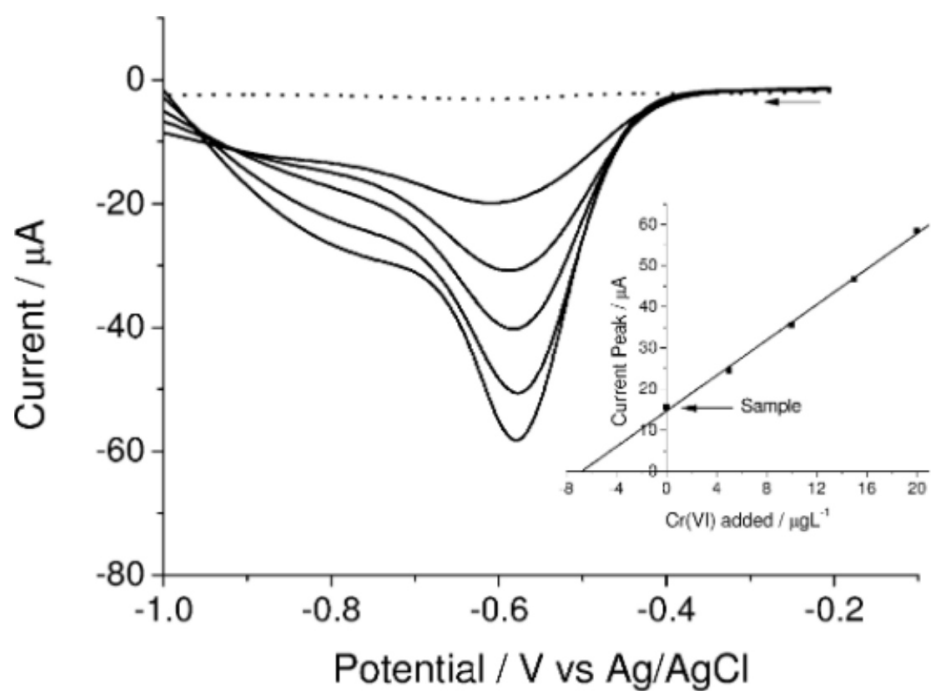

Fig. 6. AdCSVs recorded at Bi-PPCE in solution of waste-water sample after UV oxidation, spiked with increasing concentrations of $\mathrm{Cr}(\mathrm{VI})$, from $5 \mathrm{mgL}^{\square 1}$ up to $20 \mathrm{mgL}^{\square}$. Other conditions are as in Figure 3.

heavy metal analysis in water [33]. Before analysis, the sample was stored at $48 \mathrm{C}$, as recommended by the standard analytical procedures [33]. The determination of total inorganic $\mathrm{Cr}$ was performed after oxidation of Cr(III) with UV radiation, as described in the Experimental section. For this analysis, $10 \mathrm{~mL}$ of the sample was diluted with $10 \mathrm{~mL}$ of acetate buffer $(\mathrm{pH} \mathrm{6})$. The oxidation was performed for 30 minute while purging with pure oxygen and irradiating with UV light. At the end of the treatment, $4 \mathrm{~mL}$ of the oxidized sample was added to the electrochemical cell containing PCV and $\mathrm{NaNO}_{3}$.

The quantification was performed using the standard addition method; the relevant AdCSVs are reported in Figure 6 together with the standard addition plot (see Inset).

The voltammograms are characterized by a well defined peak which scales linearly with the $\mathrm{Cr}(\mathrm{VI})$ concentration. The presence of a shoulder at more negative potential values can be attributed to other species present in solution such as vanadium and aluminum which could be complexed by PCV as well [32]. However, the presence of these elements does not interfere with the quantitative detection of $\mathrm{Cr}$. The concentration of total inorganic $\mathrm{Cr}$ in the sample was $144 \square 1 \mathrm{mgL}^{\square 1}(\mathrm{n}=3)$; this value is in satisfactory agreement with the result obtained by ICPOES that was $143 \square 2 \mathrm{~mL} \mathrm{~L}^{\square 1}(\mathrm{n}=3)$.

\subsection{Analysis of $\mathrm{Cr}(\mathrm{VI})$ in Tap Water}

The concentration of $\mathrm{Cr}(\mathrm{VI})$ in drinking water is limited by the WHO at a value of $50 \mathrm{mgL}^{\square 1}$ [34] and even more restrictive limits have been recently proposed. For instance, the California Department of Public Health [35] set this value to $10 \mathrm{mgL}^{\square 1}$. The presently used standard method [33] is based on the complexation of $\mathrm{Cr}(\mathrm{VI})$ with ammonium pyrrolidine dithiocarbamate (APDC) followed by extraction with methyl isobutyl ketone (MIBK).
The extract is aspirated into the flame of an atomic absorption spectrophotometer. This method presents a DL of $0.02 \mathrm{mgL}^{\square 1}$, which is comparable with the DL of the method we propose here, but the standard method requires a more complex analytical procedure.

The determination of $\mathrm{Cr}(\mathrm{VI})$ was performed in a sample of tap water from the Venice municipal pipelines spiked with $12 \mathrm{mgL}^{\square 1}$ of $\mathrm{Cr}(\mathrm{VI})$ added as chromate salt. The sample was filtered $(0.45 \mathrm{~mm})$ and analyzed (not later than 24 hours after the sampling and spiking) with the proposed electroanalytical method and with the standard spectroscopic method.

The concentration of $\mathrm{Cr}(\mathrm{VI})$ in the sample, quantified with the standard addition method (see Figure 7) was $12.0 \square 0.2 \mathrm{mgL}^{\square 1}$ (average of 3 different measurements $\square$

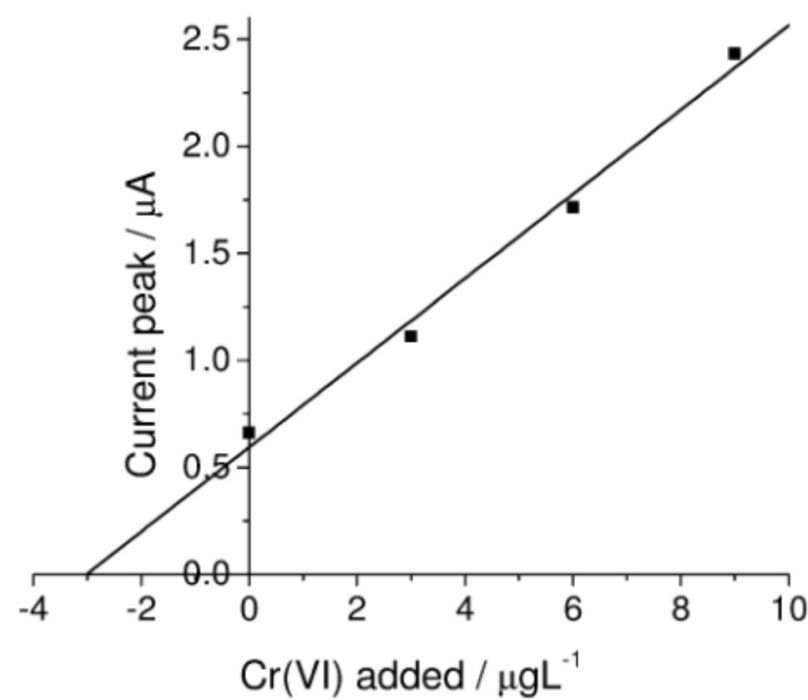

Fig. 7. Standard additions plot for spiked tap water. Sample dilution $1: 4$. Conditions: accumulation $\square 0.2 \mathrm{~V}$ for $60 \mathrm{~s}$, cleaning step $\square 1.4 \mathrm{~V}$ for $20 \mathrm{~s}$. Other conditions are as in Figure 3. 


\section{Full Paper}

relative standard deviation). This value is in very good agreement with the concentration of $12.0 \square 0.1 \mathrm{~mL} \mathrm{~L}^{\square 1} \mathrm{ob}$ tained with the standard method.

\section{Conclusions}

PPCEs show promising electroanalytical performance for the electrochemical determination of electroactive analytes at trace concentration levels. Similarly to glassy carbon electrodes, they are characterized by a wide potential window and low reactivity. Furthermore, PPCEs display several advantages since they can be prepared in customized shape and size and can be miniaturized to extreme levels. PPCEs can be easily modified by bismuth deposition to obtain Bi-PPCEs which allow the successful AdCSV determination of $\mathrm{Cr}(\mathrm{VI})$ with high selectivity and sensitivity. The method developed here displays a satisfactory dynamic range with a low detection limit. Furthermore, the possibility to customize the electrodic material presents a very good option for on-line environmental measurement.

\section{Acknowledgements}

The authors thank Dr. P. Schiavuta (Veneto Nanotech) for skillfull assistance in the AFM measurements and Dr. F. Zanon (ARPA Veneto) for the spectroscopic measurements in tap water. Financial support by Veneto Region and MIUR (Project PRIN 2010AXENJ8) is gratefully acknowledged.

\section{References}

[1] J. Wang, J. Lu, S. B. Hocevar, P. A. M. Farias, B. Ogorevc, A nal. Chem. 2000, 72, 3218.

[2] Ø. Mikkelsen, K. H. Schrøder, Electroanalysis 2001, 13, 687.

[3] M. A. Nolan, S. P. Kounaves, Anal. Chem. 1999, 71, 3567.

[4] Ø. Mikkelsen, S. M. Skogvold, K. H. Schrøder, M. I. Gjerde, T. A. A arhaug, A nal. Bioanal. Chem. 2003, 377, 322.

[5] I. Švancara, M. Matoušek, E. Sikora, K. Schachl, K. Kalcher. K. Vytřas, Electroanalysis 1997, 9, 827.

[6] A. Charalambous, A. Economou, Anal. Chim. Acta 2005, $547,53$.

[7] I. Švancara, L. Baldrianov $\square$ E. Tesařov $\square$ S. B. Hočevar, S. A. A. Elsuccary, A. Economou, S. Sotiropoulos, B. Ogorevc, K. Vytřas, Electroanalysis 2006, 18, 177.

[8] A. Mardegan, S. Dal Borgo, P. Scopece, L. M. Moretto, S. B. Hočevar, P. Ugo, Electrochem. Commun. 2012, 24, 28.

[9] M. Bučkov $\square$, P. Gr $\llbracket$ ndler. G.-U. Flechsig, Electroanalysis $2005,17,440$.

[10] E. A. Hutton, S. B. Hočevar, B. Ogorevc, M. R. Smyth, Electrochem. Commun. 2003, 5, 765.
[11] E. A. Hutton, B. Ogorevc, S. B. Hočevar, M. R. Smyth, A nal. Chim. Acta 2006, 557, 57.

[12] M. Korolczuk, I. Rutyna, K. Tyszczuk, Electroanalysis 2010, 22, 1494.

[13] G. M. S. Alves, J. M. C. S. Magalh1/es, H. M. V. M. Soares, Electroanalysis 2013, 25, 1247.

[14] A. Mardegan, S. Dal Borgo, P. Scopece, L. M. Moretto, S. Hocevar, P. Ugo, Electroanalysis 2013, 25, 2471.

[15] M. G. Paneli, A. Voulgaropoulos, Electroanalysis 1993, 5, 355.

[16] C. M. A. Brett, A. M. C. F. Oliveira Brett, J. L. C. Pereira, Electroanalysis 1991, 3, 683.

[17] J. Wang, Analytical Electrochemistry, Wiley-VCH, New York, USA, 2006.

[18] J. Golimowski, P. Valenta, H. W. N $\square$ rnberg, Z. A nal. Chem. $1985,322,315$

[19] S. Sander, T. Navr til, L. Novotný, Electroanalysis 2003, 15, 1513.

[20] J. Wang, J. Lu, K. Olsen, Analyst 1992, 117, 1913.

[21] O. Dom nguez, M. J. Arcos, Anal. Chim. Acta 2002, 470, 241.

[22] D. V. Vukumanovic, G. W. V. Loon, K. Nakatsu, D. E. Zoutman, Microchem. J. 1997, 57, 86.

[23] V. Pifferi, F. Spadavecchia, G. Cappelletti, E. A. Paoli, C. L. Bianchi, L. Falciola, Catal. Today 2013, 209, 8.

[24] E. Chatzitheodorou, A. Economou, A. Voulgaropoulos, Electroanalysis 2004, 16, 1745.

[25] E. O. Jorge, M. M. Rocha, I. T. E. Fonseca, M. M. M. Neto, Talanta 2010, 81, 556.

[26] S. Ranganathan, R. McCreery, S. M. Majji, M. Madou, J. Electrochem. Soc. 2000, 147, 277.

[27] C. Wang, G. Jia, L. Taherabadi, M. Madou, J. Microelectromech. Syst. 2005, 14, 348 .

[28] C. Wang, L. Taherabadi, G. Jia, M. Madou, Y. Yeh, Electrochem. Solid-State L ett. 2004, 7, A 435.

[29] A. Mardegan, R. Kamath, S. Sharma, P. Scopece, P. Ugo, M. Madou, J. Electrochem. Soc. 2013, 160, B 132.

[30] http://www.microchem.com/pdf/SU -82000D ataSheet2025thru2075Ver4.pdf

[31] M. Silvestrini, A. Mardegan, R. Kamath, M. Madou, L. M. Moretto, S. Passamonti, P. Scopece, P. Ugo, Electrochim. Acta 2014, 147, 401.

[32] M. C. Vargas, O. Dominguez, M. J. Arcos, Helv. Chim. Acta 2003, 86, 2434.

[33] M. Belli, D. Centioli, P. De Zorzi, U. Sansone, S. Capri, R. Pagnotta, M. Pettine, Metodi Analitici per le acque, APAT, Roma, 2004, p. 202.

[34] http://www.who.int/water_sanitation_health/dwq/chemicals/ chromium.pdf

[35] http://www.cdph.ca.gov/certlic/drinkingwater/Pages/Chromium6.aspx 